Article

\title{
Evaluation of Rapid Exit Locations Based on Veer-Off Risk for Landing Aircraft
}

\author{
Sameera Galagedera ${ }^{1, *}$, Varuna Adikariwattage ${ }^{2}$ and H. R. Pasindu ${ }^{1}$ \\ 1 Department of Civil Engineering, University of Moratuwa, Moratuwa 10400, Sri Lanka; pasindu@uom.lk \\ 2 Department of Transport \& Logistics Management, University of Moratuwa, Moratuwa 10400, Sri Lanka; \\ varunaa@uom.lk \\ * Correspondence: 168008C@uom.lk; Tel.: +94-269-5301; Fax: +94-76-761-3255
}

Citation: Galagedera, S.;

Adikariwattage, V.; Pasindu, H.R.

Evaluation of Rapid Exit Locations Based on Veer-Off Risk for Landing Aircraft. Sustainability 2021, 13, 5134. https://doi.org/10.3390/su13095134

Academic Editors: Laura Moretti and Maria Vittoria Corazza

Received: 30 March 2021

Accepted: 25 April 2021

Published: 4 May 2021

Publisher's Note: MDPI stays neutral with regard to jurisdictional claims in published maps and institutional affiliations.

Copyright: (c) 2021 by the authors. Licensee MDPI, Basel, Switzerland. This article is an open access article distributed under the terms and conditions of the Creative Commons Attribution (CC BY) license (https:/ / creativecommons.org/licenses/by/ $4.0 /)$.

\begin{abstract}
Rapid exit taxiways enhance runway operational capacities by means of reducing the runway occupancy times of aircraft. The selection of rapid exit taxiway locations is important to achieve the optimum runway capacity. This paper presents a methodology for locating rapid exits based on excursion risk. Considering the level of severity and frequency of historical runway-related accidents and emerging use of rapid exit taxiways in the future, this study explores the associated veer-off risk at rapid exits. The proposed methodology estimates veer-off risk using three successive steps such as event probability, location probability, and severity estimation. An existing logistic regression model developed for landing overrun probability estimation is adapted for the exit taxiway facility to estimate event probability. Aircraft touchdown speed, deceleration, and runway criticality factor are the important operational parameters of this model adaptation. The aircraft turn path radius and kinetic energy at the time of veer-off are used to estimate the respective location probabilities and accident severities. As the sample analysis proves, the associated veer-off risk increases when the exits are closer to the runway threshold. The paper recommends wider taxiways and larger taxiway radii to compensate for increasing veer risks. The methodology helps for planning risk-based rapid exit taxiways for varying design, operational, and weather conditions.
\end{abstract}

Keywords: rapid exit taxiway; excursion; overrun; veer-off

\section{Introduction}

Worldwide, annual air passenger demand has consistently increased at an average rate of $6 \%$ per year over the last decade [1]. Growing air traffic volumes need sufficient operational capacities of airport airside and landside facilities. Inadequate airport capacities to meet respective air traffic demands cause airport operational issues such as congestions and delays that plague the aviation system at many major airports around the world [2]. According to Dray (2020), runway capacity is the stringent constraint on demand [3]. However, when it comes to capacity expansion, there are many constraints such as funding, land acquiring, environmental, approval granting, local campaigns etc., which complicate real world airport expansion projects such as constructing new runways. Rapid exit (or high speed exit (HSE)) taxiways have been explored as one of the most sustainable options among the airport airside capacity expansion efforts for maximizing runway operational capacities [3].

With growing air traffic volumes, rapid exit taxiways can serve up to a certain level of air traffic movements. It depends on the fleet mix, existing runway length, peak hour traffic, etc. However, rapid exit taxiway is a preferred solution for resource optimization. It saves millions of dollars in construction, land acquiring, and administration costs in terms of a completely new runway. Additionally, avoiding a larger construction project would save water, soil, air, and the environment in both direct and indirect ways. In the operational stage, high-speed exits facilitate aircraft to leave the runway faster. It may minimize unnecessary runway occupancies and taxiing. This would again save time, fuel, 
cost, and labor. Thus, rapid exit taxiways are an alternative way of approach on runway capacity management that conform to the elements such as responsible consumption, sustainable transport, bio diversity, etc. under the theme of sustainable development goals.

Accordingly, similar to recent rapid exit taxiway project completions at Riga airport, Latvia and Chennai airport, India, it is envisaged that constructing rapid exit taxiways would further increase in the future, as it would significantly contribute to increasing runway operational capacity [4]. The geometric characteristics of the rapid exit taxiways enable aircraft to exit at higher speeds than the $90^{\circ}$ exits and thereby reduce runway occupancy times [5]. Thus, to gain the maximum benefit of a rapid exit taxiway, the exit location is highly important. When a number of aircraft types are operated on the same runway, it is not as simple as positioning rapid exits further toward the runway landing threshold. The optimal number of exits and optimal locations depend on the aircraft fleet and their mix at a given runway facility. According to Clemmer in 2018, the Aircraft Design Group (ADG) is the best variable for determining rapid exit taxiway locations [6].

Due to various operational and design factors, aircraft performances may not be consistent at individual landing operations. Additional variability is induced by human factors that also play a key role in landing operations and exit maneuvers [6]. Thus, even though ATC clearance may be given to an aircraft to land and vacate though a designated exit, aircraft operational factors at the start of the high-speed turn may flout the intended design figures. Depending on the variations, aircraft may vacate through the planned exit taxiway or not. When excessive variations exist, if it is still turned into the taxiway throat, the aircraft turn path can deviate from the taxiway design path. Such centerline deviations might lead to veer-off accidents if the aircraft is unable to be stopped within the paved taxiway area. This is identified as a critical excursion risk associated with rapid exit taxiways.

Research studies conducted under the Airport Cooperative Research Program (ACRP) initiated various risk modeling for aircraft excursion risk analysis. These studies evaluate the impact of runway geometric characteristics such as length, width, runway end safety areas, and taxiway separation rules on aircraft excursion risks [7]. These and other related studies have been helpful to evaluate the adequacy of airfield facilities such as runway end safety areas and taxiway designs in order to minimize the corresponding excursion risk. The same approach further is beneficial for the modifications to accommodate an increased number of flight movements and new larger aircraft [7,8].

Even though rapid exit taxiway is a sustainable option in runway capacity management, increasing the utilization of rapid exit taxiways may cause a substantial number of incidents at rapid exit taxiways. Considering the potential danger at these high-speed exit taxiways, it is also pertinent to evaluate the relative impact of design elements of the rapid exits. Identifying the importance of rapid exit taxiways and their safety concerns, the latest draft FAA Advisory circular on Airport Design also highlights risk-based designs of exit taxiways [9]. The circular has specifically mentioned risk considerations of high-speed exits in a separate section, and it presented designs for exit locations, separation distances, acute angles, fillets, and taxiway geometries with regard to minimum risk. This is in line with their recommendations for widening high-speed exit throats as well. However, apart from the FAA focus on exit taxiways, there has been limited research conducted to investigate excursion risk at rapid exit taxiways. There is a need to research in this rapid exit taxiway-related area considering the increased usage of HSE. It will provide direct benefits for the majority of stakeholders in the air transport industry such as airports, airlines, pilots, and controllers. These may motivate the studying of this research area and focusing on the research gap in risk analysis at rapid exits. The proposed methodology is to evaluate rapid exit locations with regard to minimum excursion risk. Expansion to accommodate additional demand and new large aircraft is constrained by land acquisition, environmental regulations, and local community concerns. Capacity enhancement by the maximum utilization of existing infrastructure is the latest direction that many airports are adopting to manage the increasing demand. High-speed taxiways play an important 
role in reducing the occupancy time of landing aircraft on the runway, thereby increasing the operational capacity. This will promote rapid exit taxiways to persist as a sustainable solution for airports worldwide, and it adheres to the sustainability of the air transport industry. Furthermore, the FAA advisory circular on airport design also highlights the need to adopt an analytical approach to evaluate the HSE geometry design, which involves a risk assessment. The analysis would incorporate possible variations in the runway operational conditions such as wet runways, as well as the aircraft operational characteristics such as exit speed, etc. Based on the analysis, we can determine the worst operational conditions for high-speed turns and the locations that would have relatively lower impact on the aircraft operational risk.

\section{Background and Literature Review}

\subsection{Aircraft Accidents}

Among the worldwide aviation accidents, about $80 \%$ of accidents were airport related and nearly $39 \%$ were on runways. Considering runway-related aircraft accidents, about $25 \%$ have occurred during landing, and $14 \%$ occurred during take-offs [10]. Overruns and veer-offs are the most common types of accidents during landing roll, and they are categorized as runway excursions. Concerning taxiway and taxilane-related accidents, most of them have occurred at curved segments [7].

Table 1 shows some recent accidents at rapid exits.

Table 1. Events at high-speed exit taxiways.

\begin{tabular}{|c|c|c|c|c|c|}
\hline Date & Aircraft Type & Airport & Accident Type & Severity & Causal Factors \\
\hline $\begin{array}{l}\text { 29-August- } \\
2011\end{array}$ & A340 & $\begin{array}{c}\text { Chhatrapati Shivaji } \\
\text { International } \\
\text { Airport, India }\end{array}$ & $\begin{array}{l}\text { Veered off from the HSE } \\
\text { taxiway }\end{array}$ & $\begin{array}{l}\text { Got struck in the } \\
\text { adjoining mud }\end{array}$ & $\begin{array}{c}\text { Taxiway surface } \\
\text { condition }\end{array}$ \\
\hline $\begin{array}{l}\text { 02-November- } \\
2011\end{array}$ & B747 & $\begin{array}{l}\text { Changi Airport, } \\
\text { Singapore }\end{array}$ & $\begin{array}{l}\text { Veered off when trying } \\
\text { to vacate the runway via } \\
\text { an HSE }\end{array}$ & No information & $\begin{array}{l}\text { Turn off speed, } \\
\text { deceleration, } \\
\text { pilot error }\end{array}$ \\
\hline $\begin{array}{l}\text { 21-September- } \\
2012\end{array}$ & A319 & $\begin{array}{c}\text { Copenhagen } \\
\text { Airport, Denmark }\end{array}$ & $\begin{array}{l}\text { Veered off from the } \\
\text { paved surface when } \\
\text { attempting to turn to } \\
\text { the HSE }\end{array}$ & No information & $\begin{array}{l}\text { Turn off speed, } \\
\text { pilot error }\end{array}$ \\
\hline $\begin{array}{l}\text { 05-December- } \\
2013\end{array}$ & B767 & $\begin{array}{c}\text { Madrid Barajas } \\
\text { Airport }\end{array}$ & $\begin{array}{l}\text { Move out of the } \\
\text { HSE taxiway }\end{array}$ & $\begin{array}{l}\text { Stopped on the } \\
\text { grassy area }\end{array}$ & Tire failure \\
\hline $\begin{array}{l}\text { 21-February- } \\
2016\end{array}$ & A320 & $\begin{array}{l}\text { Birmingham } \\
\text { International } \\
\text { Airport }\end{array}$ & $\begin{array}{l}\text { Failed to negotiate the } \\
\text { taxiway turn }\end{array}$ & $\begin{array}{l}\text { Ran on to the } \\
\text { adjoining grass }\end{array}$ & $\begin{array}{l}\text { Turn off speed, wet } \\
\text { surface, pilot error }\end{array}$ \\
\hline 18-July-2016 & STINSON 108 & $\begin{array}{c}\text { Haines Airport, } \\
\text { Alaska }\end{array}$ & $\begin{array}{l}\text { When turning in to the } \\
\text { HSE taxiway, an abrupt } \\
\text { turn could not control } \\
\text { the airplane }\end{array}$ & $\begin{array}{c}\text { Substantial } \\
\text { damage to the left } \\
\text { landing gear and } \\
\text { collapsed left } \\
\text { wheel axle }\end{array}$ & Wind, ground speed \\
\hline 02-July-2019 & A320 & $\begin{array}{c}\text { Mangalore } \\
\text { International } \\
\text { Airport, India }\end{array}$ & $\begin{array}{l}\text { Aircraft veered off the } \\
\text { taxiway when turning } \\
\text { into high-speed exit } \\
\text { taxiway from } \\
\text { the runway }\end{array}$ & $\begin{array}{l}\text { No severe } \\
\text { damages }\end{array}$ & $\begin{array}{l}\text { Turn off speed, } \\
\text { deceleration, } \\
\text { pilot error }\end{array}$ \\
\hline $\begin{array}{l}\text { 21-November- } \\
2019\end{array}$ & B737 & $\begin{array}{l}\text { Odessa Airport, } \\
\text { Ukraine }\end{array}$ & $\begin{array}{l}\text { Traveled off the side of } \\
\text { the runway }\end{array}$ & $\begin{array}{l}\text { Aircraft left main } \\
\text { landing gear struck } \\
\text { on the grass }\end{array}$ & $\begin{array}{c}\text { Mechanical failure of } \\
\text { the nose } \\
\text { landing gear }\end{array}$ \\
\hline
\end{tabular}


When rapid exit taxiways-related aircraft accidents are considered, research found very few accidents. Rapid exits or high-speed exit taxiways are still not available in each and every airport. In the majority of airports, rapid exits are configured into the existing runway when the aircraft movement increases and meet to the maximum capacity. Further, available rapid exit taxiways may also be underutilized at non-congested airports. Pilot choice still holds the dominant role for exit selection and use. This helps to avoid rapid exits when a pilot experiences loss of self-confidence to use any exit at varying operational conditions. Indeed, the lower number of traffic volume caused fewer accidents at rapid exits. Furthermore, some accidents during high-speed maneuvering at rapid exit taxi-in are reported as runway-related accidents. Similarly, accidents at taxi-out into the parallel taxiway are reported as ground collisions. A few accident reporting issues were also observed, and they were filtered.

Although there are fewer current accident statistics at rapid exits, aircraft accidents at these exit may increase with growing aircraft volumes using rapid exits. High-speed turning maneuvers are much more complex than the normal landing phase as it needs added roles to recognize high-speed direction change. Hence, incidents may be expected at rapid exits once they are fully occupied.

\subsection{Excursion Risk Analysis Studies}

With the realization of the significance of the landing excursion events on the air transport industry, several studies developed methodologies to evaluate aircraft excursion risks. The first such study was by Kirkland (2001), who developed a landing overrun probability model using as the only factor the excess distance available between the end of the required landing distance and runway end as a percentage of the required landing length [12]. One significant improvement of Wong's model over Kirkland's model is the use of multiple input variables related to airport, aircraft, and weather [13].

In 2008, Hall et al. initiated risk modeling under the Airport Cooperative Research Program (ACRP) 03 for aircraft overruns [8]. This model included the factors of ambient temperature and rain with respect to Wong's model [14]. Guerra (2008) developed risk contours around airports. He conducted a probabilistic analysis on aircraft stopping locations as per the touchdown location [15]. Guerra's model estimates the probability of an aircraft stopping at point $\mathrm{B}(\mathrm{XB}, \mathrm{YB})$ when it touched the runway at a given point $\mathrm{A}$. Van Es (2009) identified a non-precision approach, touchdown beyond the threshold, excess approach speed, visual approach, tailwind, wet/flooded runway, and/or snow/ice/slushcovered runway as the causal factors for runway excursion events [14]. He developed a risk index based on the risk factors. The associated weight of risk factors was estimated in terms of risk ratio, which is the rate of the accident probability with the factor present over the accident probability and without the same factor present. The ACRP 03 empirical approach was further expanded for veer-off risk modeling by Ayres et al. (2011) under ACRP 50 [7]. Variable categories such as airport, aircraft, flight data, weather, wreckage location, and consequence-related factors have been taken as input parameters in these risk models.

In 2014, Ayres et al. developed a risk assessment and reporting template especially for runway veer-offs at landings and take-offs [16]. Ayres' accident probability model was further modified in the study of "advanced risk assessment of runway safety areas with enhanced algorithm" [17]. Furthermore, it includes thunderstorm as a new independent variable. Using recent accident data, Shirazi et al. developed a risk assessment tool for Runway Protection Zones [18]. The models developed in this tool can be used for landing overrun, undershoot, take-off overrun, and take-off overshoot assessments. Moretti et al. (2017) developed a methodology for runway veer-off risk assessment considering key variables of air traffic, wind distributions, landside building interferences, and geotechnical characteristics of the strip areas [19]. The exponential probability models compute the probability that an aircraft veer-off occurs, and it is at a certain distance from the runway centerline. Based on the California Bearing Ratio (CBR) of the subgrade, damages to 
both human health and aircraft conditions, a damage matrix was developed to estimate respective veer-off consequences. A one significant improvement of this matrix was the incorporation of soil-bearing capacity into the respective consequences classification. The study for topological risk mapping of runway overruns was a probabilistic approach to assess runway overruns. In this approach, the runway end was divided into grids, and each was assessed two dimensionally. The expected kinetic energy of the aircraft at a given grid has been considered as the severity index. This approach has focused on detailed planning of airport safety areas [20].

\subsection{Rapid Exit Location}

Exit locations and the number of exits are the key determinants with regard to the aircraft fleet mix for vacating through rapid exits. Several studies have been done on rapid exit location selection. Schoen et al. (1985) developed a probabilistic model to optimal runway turnoffs [21]. Using this approach, aircraft travel path coordinates in the turning maneuver can be found. Aircraft wheelbase, weight, load on nose gear, wingspan, exit speed, and deceleration were the input parameters into the mode. In 1990, Trani et al. developed a computer-based simulation for the optimization program "Runway Exit Design Interactive Model" (REDIM) for locating optimal rapid exit locations [22]. This REDIM can be used for planning exit locations for user-defined aircraft populations at various airport settings. According to Trani et al. (1992), significant ROT reduction could be observed with more than three optimally located exits [23]. Additionally, aircraft exit speeds up to $35 \mathrm{~ms}^{-1}$ are feasible for aircraft TERP categories C and D. Furthermore, smaller exit angles (acute angles) need to ensure respective lateral separations between the runway and parallel taxiway centerline and adequate decelerating length up to the taxing speed. The proposed exit angles are $17^{\circ}$ to $30^{\circ}$ [22]. The second phase of the REDIM was developed in 1992 with the added flexibility for user-defined exit angles [23]. This study points out differences in aircraft landing performances even if they belong to the same TERP category. According to Trani et al., a 15\% ROT reduction can be achieved using superacute angle $\left(20^{\circ}\right)$ exits rather a $30^{\circ}$ angle [23]. Rammohan and Mahesh (2007) developed guidance for determining locations for rapid exit taxiways. This is a theoretical approach following ICAO's three-segment method and fundamental equations for motion [24]. To evaluate the effect of the reconfiguration of an exit taxiway, runway capacity analysis was done by Rahim (2015) for an international airport in Indonesia [25]. The analysis proved that the new rapid exit taxiway configuration could increase runway capacity from 21 to 28 aircraft movements. Using Airport Surface Detection Equipment data from the 36 largest airports in the US, Nicholas et al. (2019) revealed that the exit location is the most influencing factor on ROT [26]. Aircraft type, airline, exit angle, final approach speed, etc., are the factors successively ranked. The demonstrated that predictive models can be used to locate new rapid exits.

Zhou and Jiang (2015) conducted a study for taxiway path optimization based on conflict detection. The analysis developed an algorithm to find the optimum taxiing path in terms of maximum operational efficiency and safety. The main focus of this study was to minimize conflicts [27]. Statistical extreme value analysis for taxiway centerline deviations of aircraft was conducted by FAA and Boeing company at Anchorage International airport (ANC) and John F. Kennedy International Airport (JFK) [28]. Two simultaneous laser measurements were taken from straight taxiway segments. The most deviations were observed from B747, and it was very similar in the two airports. The same study developed a formula to estimate the two-sided risk of exceeding a specified threshold for taxiing B747 aircraft in a straight taxiway segment [28]. Considering the importance of centerline deviation of taxing aircraft, Young (2014) has also initiated a study in collaboration with FAA to assess such deviations during unintentional adverse wind conditions or intentional turning maneuvers at exit taxiways [29]. 


\subsection{Rapid Exit Design}

Taxiway exit angle (acute angle), taxiway radius, and runway-parallel taxiway separation are key geometrical characteristics of rapid exits. According to ICAO (2005), the acute angle should not be greater than $45^{\circ}$, and preferably, it should be $30^{\circ}$ [5]. For the recommended $30^{\circ}$ acute angle exits, the associated design radius for code number 3 and 4 runways is $550 \mathrm{~m}$ (Figure 1) and $26.7 \mathrm{~m} / \mathrm{s}$ exit speed is preferred [5].

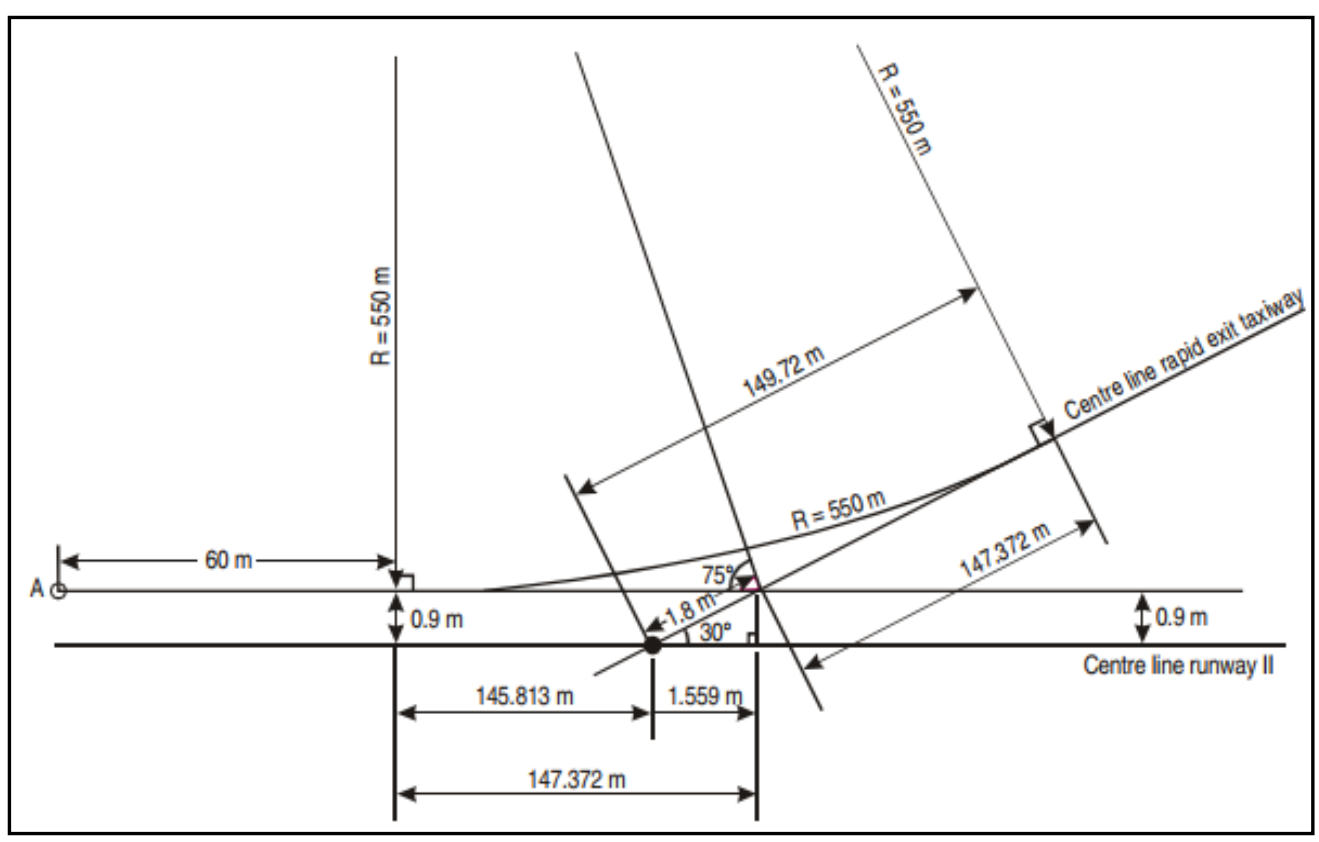

Figure 1. High-speed exit design for code number 3 and 4 (Source: ICAO Design Manual [5]).

The FAA recommends the same $30^{\circ}$ acute angle with a $450 \mathrm{~m}$ taxiway radii [24]. However, the minimum turn radii are based on the Taxiway Design Group (TDG). This TDG depends on the separation between runway and a parallel taxiway. This separation is an important design element especially at super-acute angles to reach safe taxiing speed or complete stopping prior to any intersection and reverse turn. To improve pilot recognition and acceptance of exit taxiways, The FAA further recommends wider exit taxiway throats and high-intensity taxiway centerline lights [30].

\subsection{Operational Risk at Rapid Exit Taxiways}

Aircraft veer-offs are defined as excessive deviations of aircraft travel paths beyond the lateral limits of the respective runway or taxiway [7]. Similarly, aircraft turn path lateral deviations can take place during the high-speed turning maneuvers at rapid exits as well. When the exit location is identified as the dominant factor for ROT reduction, exit speed is the critical factor of safe maneuvering [31]. If an aircraft is unable to reach the recommended exit speed at the starting point of an exit taxiway and the aircraft speed is excessively high, aircraft may not turn into the rapid exit. Nevertheless, if an aircraft speed at the starting of the turning maneuver is moderately higher than the recommended speed, aircraft may be turned into the taxiway throat. In such situations, the aircraft travel path may deviate from the taxiway centerline. Other than the aircraft speed, various design and operational factors such as deceleration, weight, surface conditions, etc. may cause turn path deviations. These excessive deviations may lead to veer-off events. However, pilot interventions may manage some events if aircraft operational parameters are at tolerable levels.

Referring to Table 1, most of the causal factors related to aircraft excursions at rapid exits are speed, deceleration, pilot error, etc. Factors such as approach speed, touchdown location, aircraft mass, and deceleration cause for greater exit speeds at the point of 
exit starts. Aircraft deceleration is affected by the pavement conditions, aerodynamic effect, weather, and pilot preparation to exit [31]. Exit taxiway location, acute angle and radii, runway-taxiway separation distances, fillets, safety areas, etc. are airfield-related design factors. These operational and design factors are important for the decisions on the respective utilizations of the available rapid exits at airports. For example, in Melbourne airport, more than $85 \%$ of aircraft vacate through the rapid exits taxiways [32]. Furthermore, in Kolkata and Mumbai airports in India, Chopin airport in Poland, and Malaga airport in Spain are worldwide examples for ongoing projects on new rapid exit taxiway constructions. Additionally, Gatwick airport, London, the busiest single runway airport in the world, is also now looking for a new rapid exit taxiway for maintaining the demanding flight schedule.

As above-mentioned, using historical accident data, various studies have developed models to evaluate aircraft excursion risks at runways. These models could be used to estimate potential risks at various operating conditions at different airport settings. However, existing models are unable to be used for estimating risk at rapid exits, and some limitations are also found for developing new models for analyzing rapid exit taxiwaysrelated risk. A lack of sufficient data regarding the previous events is one such limitation. Aircraft exiting through a particular rapid exit is still taking place with the choice of the pilot, which is related to his experience and familiarity on runways. Thus, available operational data also represent the highly subjective pilot decision-making element. Thus, this paper presents a novel quantitative risk analysis-based approach for location selection for rapid exit taxiways.

\section{Methodology}

\subsection{Evaluation of Veer-Off Risk}

Risk is defined in terms of the estimated probability of an event and the corresponding severity of the consequences of a hazard. Accordingly, risk is defined in terms of a set of triplets as per Equation (1).

$$
R=\left\{\left(P_{i}, S_{i}, X_{i}\right)\right\}
$$

where $P_{i}$ is the probability that an aircraft is unable to reach the design exit speed at the point of exit. $S_{i}$ is the aircraft travel path probability, which is beyond the design taxiway path and belongs to a defined airfield area, and $X_{i}$ is the event consequence. Distinct consequences $\left(X_{i}\right)$ depend on the types of undesirable events. In this study, consequences are related with the aircraft travel distance on the unpaved airfield terrain. This travel distance depends on the kinetic energy of the aircraft at the veer-off. Accordingly, this section presents the methodology (Figure 2) to evaluate aircraft veer-off risk at rapid exit taxiways. 


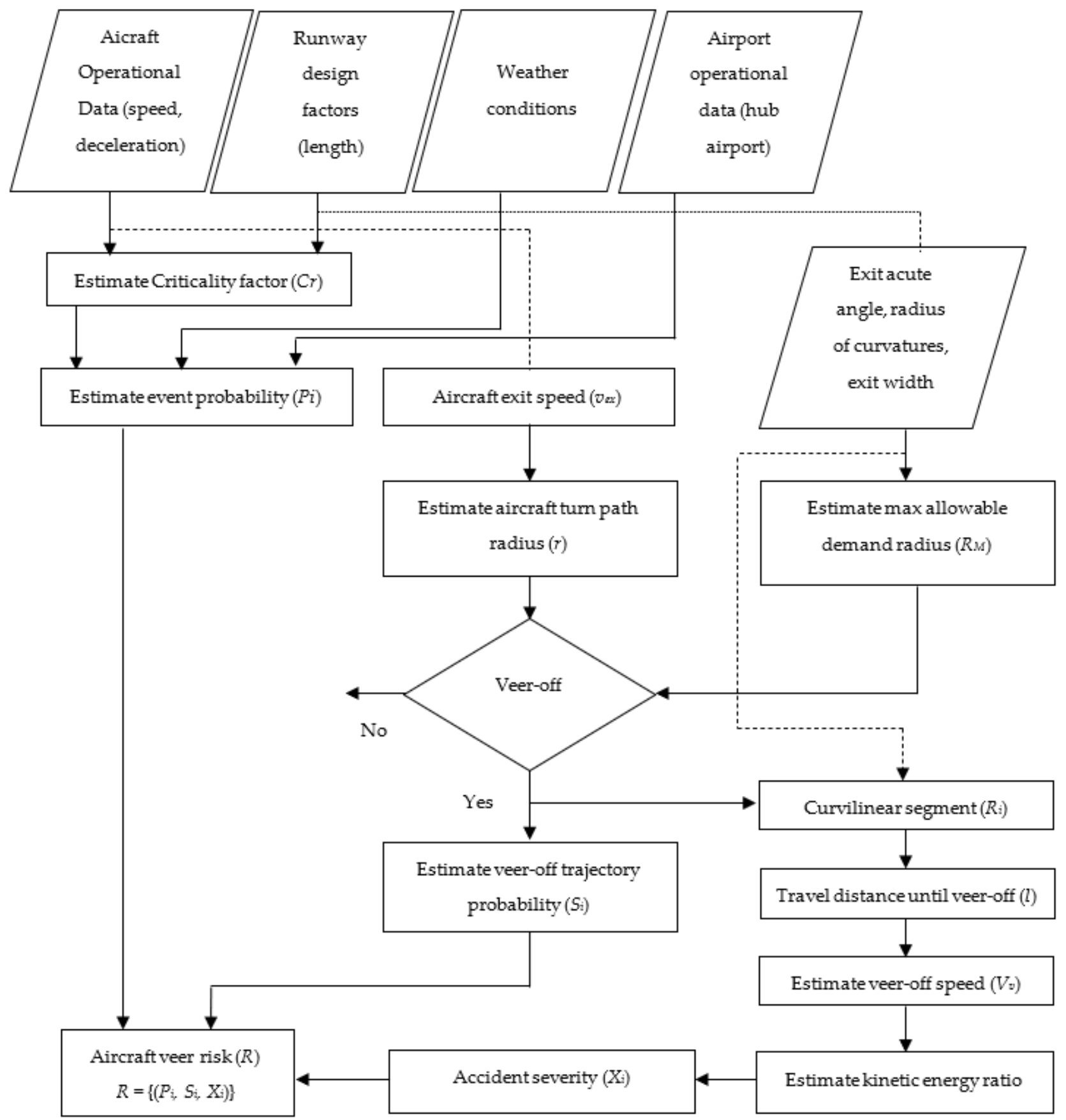

Figure 2. Flow chart of the methodology.

\subsection{Estimation of Event Probability $\left(P_{i}\right)$}

This section presents the methodology that is going to be used for aircraft event probability estimation. The majority of the event probability modeling uses historical accident statistics for model calibration. Since the available accident data attached to rapid exits are insufficient to model calibration, this study used an existing event probability model. Among the various event probability models, the overrun probability model can be adapted into this high-speed exiting scenario. Multivariate overrun probability models estimate the corresponding probability of an aircraft run off the runway end. It indirectly measures the probability that an aircraft is unable to stop within the available runway length. Using the same approach, the probability that an aircraft is unable to reduce its speed to a certain speed (instead of zero speed) in a given runway length can be estimated. 
As the FAA recommends, there is a direct relationship between the aircraft speed at curved taxiways and the corresponding taxiway radius [30]. According to the argument developed here, that the aircraft reaches the recommended design exit speed at or before the point of exit is a critical determinant, and all these operations can safely follow the designed taxiway centerline path. Conversely, if an aircraft is unable to reach the recommended exit speed at or before the point of exit, it may cause it to travel along a larger turn path radius. Likewise, when an aircraft travel path deviates from the taxiway centerline path, such occurrences could be identified as events. Thus, aircraft operations in which exit speeds are greater than the recommended exit speed are classified as events. Due to various design, operational, and weather reasons, the corresponding probability that an aircraft is unable to reach the recommended exit speed at the point of exit is defined as the event probability.

With some alternations, the multivariate overrun probability model (Equation (2)) developed by Shirazi et al. is used to estimate event probabilities. Thus, using the landing overrun model, the respective probabilistic effect of the aircraft, airport, and weatherrelated factors on the exit speed for exceeding the recommended speed is estimated. As such greater exit speeds cause travel path deviations, the same probability estimation is equal to the respective probability of taxiway deviations [19]. One major assumption made here is that the factors that cause exceeding the zero speed at the end of the available runway length have an identical influence on exceeding the recommended exit speed at a given exit location. Furthermore, there is an equivalent effect of the corresponding risk factors on the respective event probabilities at these distinct locations. This basic model can be recalibrated using rapid exits-related specific data as part of future research. This multivariate probability model counts airport and aircraft design factors, aircraft operational, and weather-related factors for overrun probability estimation, which becomes an advantage by using the multivariate risk model.

$$
\mathrm{P}(\text { aircraft not reach to the recomended exit speed })=\frac{1}{1+\mathrm{e}^{-Z}}
$$

$\mathrm{Z}=-11.96-3.32(\mathrm{hub})+1.71($ foreign $\mathrm{O} / \mathrm{D})-1.18$ (aircraft class A) +2.25 (piston) -1.22 (prop) +1.6 (fog) +1.50 (icing) +1.61 (night) +0.76 (rain) +1.57 (snow) -1.23 (electric storm) -0.86 (temperature greater than $25 \mathrm{C}$ ) +0.94 (tailwind between 5 and $12 \mathrm{kts})+3.22$ (tailwind greater than $12 \mathrm{kts})+1.60$ (visibility less than $2 \mathrm{SM})+0.98$ (visibility between 2 and $4 \mathrm{SM}$ ) -1.11 (crosswind between 2 and $5 \mathrm{kts}$ ) -0.47 (crosswind between 5 and $12 \mathrm{kts})+5.82$ (criticality factor).

Considering different risk factors in the Shirazi's landing overrun probability model, the runway criticality factor is expressed by Equation (3). For a given aircraft, the ratio between the required runway length to complete the landing operation at a runway and the available runway length at the same runway is measured by the criticality factor. For a given runway, the criticality factor depends on the required runway length. The type of aircraft and weather conditions are key determinant factors on the runway required length.

$$
\text { Runway Criticality factor }(C r)=\frac{\text { Runway length required }\left(l_{R}\right)}{\text { Runway length avalaible }\left(l_{a}\right)}
$$

The landing length required for an aircraft implies the required runway length for the completion of all four segments (approach, flare, transition, and full braking) of the landing phase. With regard to the full braking segment, it is the aircraft stopping distance. Alternatively, it can be considered as the length required to reach zero speed. Thus, $l_{R}$ could be considered as the length required to become zero speed.

In this analysis, the concept explored by Equation (3) is used to adapt Equation (2) for rapid exits-related risk estimation. The original use of runway criticality factor in Equation (2) is to measure the adequacy of available runway length for a given type of aircraft landing. In this analysis, the runway criticality factor is used to measure the adequacy of the distance from threshold to the exit for reaching the recommended exit speed at a given exit configuration. Thus, using the same concept, the corresponding 
numerator and denominator terms are modified. Considering the recommended exit speed for a given exit geometry, the touchdown speed, and the required landing length at a given airport, the required exit length for the recommended exit speed is estimated in Equation (6) using fundamental equations of motion (Equations (4) and (5)).

The length required to reach the recommended exit speed is estimated as

$$
v_{R}^{2}=u^{2}-2 \times a \times l_{E R}
$$

The runway length required to reach to zero speed is estimated as

$$
0=u^{2}-2 \times a \times l_{0}
$$

In this approach, it is assumed that the deceleration during the landing roll is constant. Using Equations (4) and (5),

$$
l_{E R}=\left(\frac{u^{2}-v_{R}^{2}}{u^{2}}\right) \times l_{o}
$$

Here,

$l_{E R}$ - Length required to reach the recommended exit speed at rapid exit taxiway $l_{0}$-Aircraft landing length required to come to a full stop at the airport condition

$v_{R}$-Recommended exit speed

$u$-Touchdown speed

$a$-Deceleration

$$
\text { Modified Criticality factor }\left(C r_{m}\right)=\frac{\text { Exit length required }\left(l_{E R}\right)}{\text { Exit length avalaible }\left(l_{a}\right)}
$$

The Modified Criticality factor $\left(\mathrm{Cr}_{m}\right)$ estimated in Equation (7) is substituted to Equation (2). The analysis assumes that the overrun probability estimated in Equation (2) at various conditions is proportionate to the probability that an aircraft is exceeding the recommended exit speed at a given exit location. The conditions that affect exceeding zero speed at a given runway length similarly affect exceeding the speed profiled along the runway length.

1. Depending on the aircraft touchdown speed and exit location, modified criticality factors can be estimated (Equation (7)).

2. Aircraft operational factors and weather factors are inserted to the overrun risk model (Equation (2)) for estimating aircraft probability, which is unable to reach the recommended exit speed at the point of exit.

\subsection{Veer-Off Trajectory Probability $\left(S_{i}\right)$ Estimation}

As explained earlier, aircraft speed at the exit point varies due to inconsistent landing operations. Several operational and design factors determine the aircraft travel path. The travel path radius mainly depends on its lateral stability. The aircraft turn path is determined by various operational, design, and weather factors. Schoen et al. developed a relationship between aircraft operational and design factors and the nose landing gear stability [21]. Accordingly, factors such as the nose gear centripetal force, aircraft inertia, and tire scrubbing resistance to turn, which is associated with the side friction, were considered. The functional relationship among the (a) nose gear tire skid friction coefficient $\left(f_{\text {skid }}\right),(\mathrm{b})$ tire scrubbing coefficient $\left(f_{\text {sc }}\right),(\mathrm{c})$ aircraft inertia contribution to nose gear skidding friction coefficient $\left(f_{I z z}\right)$, and $(\mathrm{d})$ centripetal acceleration contribution to skidding $\left(f_{c}\right)$ is expressed by Equation (8) [21]. It is assumed that aerodynamic forces are insignificant at these turning speeds [22].

$$
f_{\text {skid }}=f_{I z z}+f_{c}+f_{s c}
$$


The contribution for the centripetal acceleration $\left(f_{c}\right)$ can be computed by Equation (9):

$$
f_{c}=\frac{v_{e x}^{2}}{g \times r}
$$

The method assumes that the effect of the scrubbing coefficient $\left(f_{s c}\right)$ and the aircraft inertia contribution to nose gear skidding friction $\left(f_{I z z}\right)$ to the side friction coefficient are negligible. Hence, the aircraft turning radius $(r)$ can be estimated by Equation (10),

$$
r=\frac{v_{e x}^{2}}{g \times f_{\text {skid }}}
$$

As Equation (11) explains, the side friction coefficient is a function of the aircraft instantaneous speed and the corresponding aircraft TERP category [22].

$$
f_{\text {skid }}=f(v, \text { terp })
$$

When aircraft exit speed is known, the aircraft travel path radius $(r)$ at the point of exit can be estimated from Equation (10). This turn path radius is the minimum aircraft nose gear travel path radius, which should be demanded by the nose wheel at that particular instantaneous speed for the lateral stability of the nose gear wheel. Therefore, this paper defines it as the demand turning radius $R_{D}$.

Using this methodology, the aircraft nose gear wheel's minimum required turn path radius (or demand turning radius) $\left(R_{D}\right)$ at the starting of the exiting maneuver (Ex start) is estimated (Figure 3). The estimated radius here is the minimum radius, and any lesser demand radius than the taxiway design radius can be corrected up to the design taxiway radius with pilot intervention. However, at greater demand turn path radiuses $\left(R_{D}\right)$, it might be doubtful for entering into the taxiway throat and following the taxiway centerline. Accordingly, some airplanes may excessively deviate from the taxiway centerline path, leading to veer-off events. Considering the taxiway width and pilot intervention, it will be a critical turn path radius that classifies potential veer-offs and safe maneuvers. The paper considers only the greater $R_{D}$ results than the taxiway centerline radius as leading to potential veer-off events and neglects all lower $R_{D}$ results. Even for the greater $R_{D}$ results, potential events are classified such as normal operation, incident, or accident based on the aircraft operational factors and taxiway design elements.

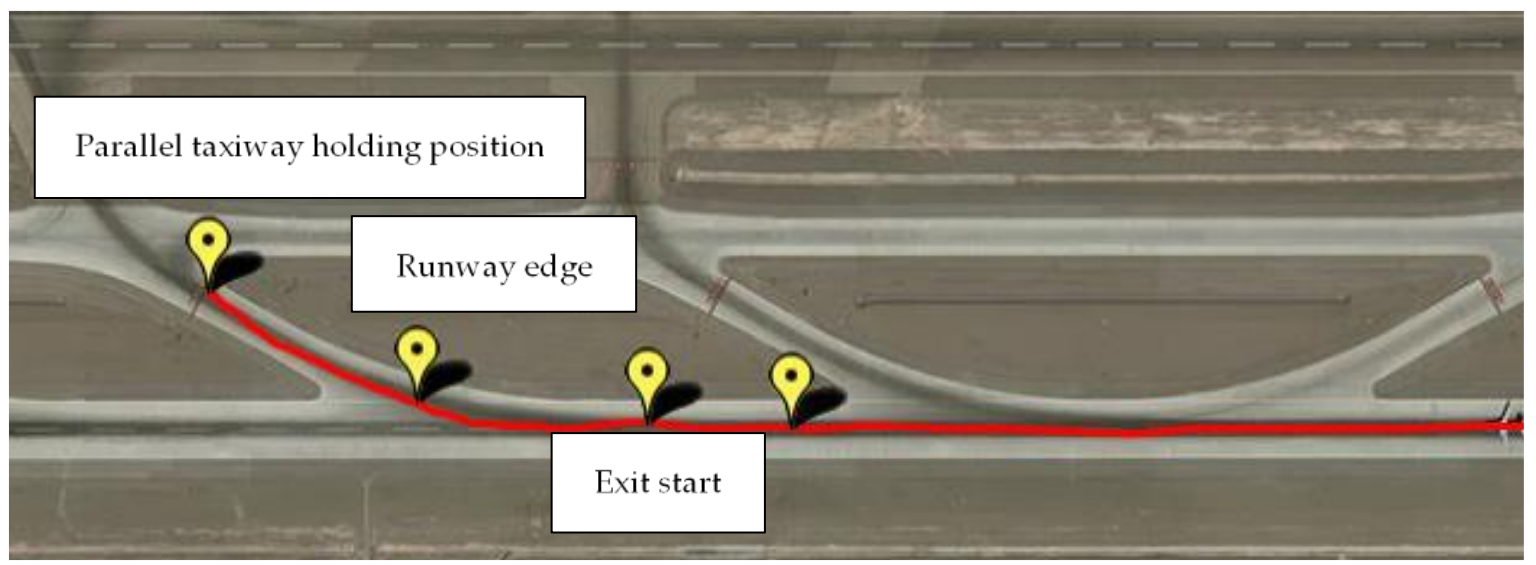

Figure 3. Turn path locations.

Based on the type of aircraft, a respective maximum allowable demand turning radius for a safer turning maneuver needs to be identified: that is the critical turn path radius. This maximum allowable turning radius is the demand turning radius that can complete the curvilinear taxiing maneuver within the paved taxiway surface (Figure 3). All other 
demand turning radii beyond the maximum allowable radius are leading to enter into the unpaved airfield terrain. The geometrically derived maximum allowable turning radius for the $B 747-400$ is $775 \mathrm{~m}$. When the type of aircraft changes, the respective maximum allowable radius will be different. This can be derived by constructing an arc connecting the exit start point and the taxiway throat outer edge (at the intersection of the runway-taxiway paved edge). The difference between the maximum allowable radius and the taxiway design radius is the runway edge crossing point. As shown in Figure 3, in the design radius, the runway edge crossing point is at the middle of the taxiway throat. In the maximum allowable radius, the runway edge crossing point moves toward the runway end up to the intersection of the runway taxiway outer edges. The arc center should be somewhere on the same perpendicular line (to the runway centerline) on which the design taxiway radius center point exists. Accordingly, this maximum turn path radius is estimated considering the least travel path radius at which the aircraft outer main gear commences to runout the paved surface. When the aircraft nose gear turning radius is lower than this maximum allowable turning radius, it does not cause the outer main landing gear wheel to leave the paved surface. Accordingly, the veer-off trajectory probability $\left(S_{i}\right)$, the number of turn paths that are greater/lower than the maximum allowable radius out of the total turning maneuvers, is estimated for the event types defined in Table 2, respectively.

1. Due to variations of various operational factors, aircraft speed at the point of exit is different. Even the known touchdown speed $\left(v_{t h}\right)$ causes different exit speeds due to the effect of deceleration and touchdown location. Aircraft deceleration during the landing roll depends on the pilot's intention to take a particular exit. Therefore, the speed at the point of exit $v_{e x}$ is given by Equation (12),

$$
v_{e x}=\left(v_{t h}^{2}-2 a l\right)^{\frac{1}{2}}
$$

where: $v_{e x}$-Speed at the point of exit $v_{t h}$-Touchdown speed $l$-Distance between the exit location and touchdown location $a$-Deceleration in the landing roll.

2. However, even for a known touchdown speed, touchdown location and deceleration may be random variables. Accordingly, at varying decelerations and touchdown locations, $v_{e x}$ is also a random variable. Thus, values for deceleration and touchdown locations for a given aircraft approach category can be taken from the following probability density function for normal distribution (Equation (13)).

$$
f(x)=\frac{1}{\sigma \sqrt{2 \pi}} e^{-\frac{(x-\mu)^{2}}{2 \sigma^{2}}},-\infty \leq x \leq \infty
$$

where $\mu$ and $\sigma$ are the mean and standard deviation of landing speed and touchdown location, respectively.

3. Random numbers are generated to simulate the different operations by the Monte Carlo simulation technique for the variables such as deceleration $(a)$ and touchdown location (l). The simulation follows Equation (13) normal distribution subject to sample parameters taken from the aircraft landing data at the given airport.

4. For different touchdown locations and decelerations, exit speeds can be estimated. Based on these exit speeds, we can estimate the number of turning paths that is beyond the maximum allowable radius: that is, the corresponding trajectory probabilities belong to the veer-off category.

$$
\text { Trajectory probability }\left(S_{i}\right)=\frac{\text { Number of operations where } \mathrm{R}_{\mathrm{D}}>775 \mathrm{~m}}{\text { Total number of simulations for } \mathrm{R}_{\mathrm{D}}}
$$


Table 2. Aircraft B747-400 location probability.

\begin{tabular}{|c|c|c|c|c|}
\hline $\begin{array}{c}\text { Turn Path Radius } \\
\text { Analysis }\end{array}$ & Event & $\begin{array}{c}\text { Critical } \\
\text { Component }\end{array}$ & Damage & Severity \\
\hline $\begin{array}{l}\text { Estimated aircraft demand } \\
\text { turning radius } \\
\left(\mathrm{R}_{\mathrm{D}}\right)<775 \mathrm{~m}\end{array}$ & $\begin{array}{l}\text { Aircraft travels along the rapid } \\
\text { exit taxiway path as the pilot can } \\
\text { manage the aircraft travel path }\end{array}$ & Outer main gear & No & No incident \\
\hline \multirow[t]{2}{*}{$\begin{array}{c}775 \mathrm{~m}<\text { Estimated aircraft } \\
\text { demand turning } \\
\text { radius }\left(\mathrm{R}_{\mathrm{D}}\right)\end{array}$} & $\begin{array}{l}\text { There is a chance that aircraft does } \\
\text { not enter into the rapid exit } \\
\text { taxiway path. However, due to the } \\
\text { aircraft speed and deceleration, } \\
\text { the aircraft stops within the paved } \\
\text { runway/taxiway surface before } \\
\text { entering the unpaved } \\
\text { adjacent terrain. }\end{array}$ & $\begin{array}{l}\text { Aircraft nose } \\
\text { landing gear }\end{array}$ & $\begin{array}{l}\text { No damage, } \\
\text { interfere other } \\
\text { operations }\end{array}$ & Incident \\
\hline & $\begin{array}{l}\text { A higher chance that the aircraft } \\
\text { does not enter into the rapid exit } \\
\text { taxiway path. Depending on the } \\
\text { turn path, the aircraft might enter } \\
\text { into the unpaved adjacent terrain }\end{array}$ & $\begin{array}{l}\text { Aircraft nose } \\
\text { landing gear }\end{array}$ & $\begin{array}{l}\text { Aircraft landing } \\
\text { gear damage due to } \\
\text { high stress at } \\
\text { soft terrain }\end{array}$ & Major \\
\hline
\end{tabular}

\subsection{Estimation of Event Severities $\left(X_{i}\right)$}

In case of a veer-off $\left(R_{D}>775 \mathrm{~m}\right)$, the aircraft stopping location is on the adjacent unpaved terrain, which cause damages to aircraft components. A longer distance on the unpaved terrain causes severe damages for the aircraft mechanical components and a shorter distance causes minor damages. The travel distance on the unpaved terrain is based on the kinetic energy available at the time of veer-off. Accordingly, this analysis proposed a severity index that is proportional to the kinetic energy ratio at the point of veer-off from the paved taxiway surface compared to the kinetic energy at the exit speed normally at the exit maneuvering start. Thus, a smaller ratio depicts a small percentage available to travel on the unpaved terrain.

In case of a veer-off incident, the aircraft speed at the point of veer-off is estimated by Equation (15):

$$
\ddot{\mathrm{V}}^{2}=v_{e x}^{2}+2 \times a \times l
$$

where

$\ddot{v}$-Veer-off speed from the paved surface $(\mathrm{m} / \mathrm{s})$,

$v_{e x}$-Turn off starting speed (speed at Ex start) $(\mathrm{m} / \mathrm{s})$,

$a$-Linear deceleration $\left(\mathrm{m} / \mathrm{s}^{2}\right)$,

l-Aircraft travel distance up to veer-off on the paved surface $(\mathrm{m})$

The values for above $l$ are geometrically estimated based on the travel path radius $R_{D}$ (Table 2). The area between the runway centerline and the exit taxiway centerline at the taxiway is divided into curvilinear segments as shown in Figure 4. Following Table 3, the aircraft demand turning radius estimated using Equation (10) is classified into one of the intervals ( $\mathrm{Rj})$. The distance from the point of exit to the point of veer-off for each segment can be taken from Table 3. It is directly used for the estimation.

Zero or negative veer-off speeds depict that the aircraft has stopped before reaching the paved taxiway/runway end. Such instances can be taken as incidents (Table 3) where demand turning radiuses are greater than the allowable maximum radius, yet it does not have enough energy to travel on the unpaved surface. 


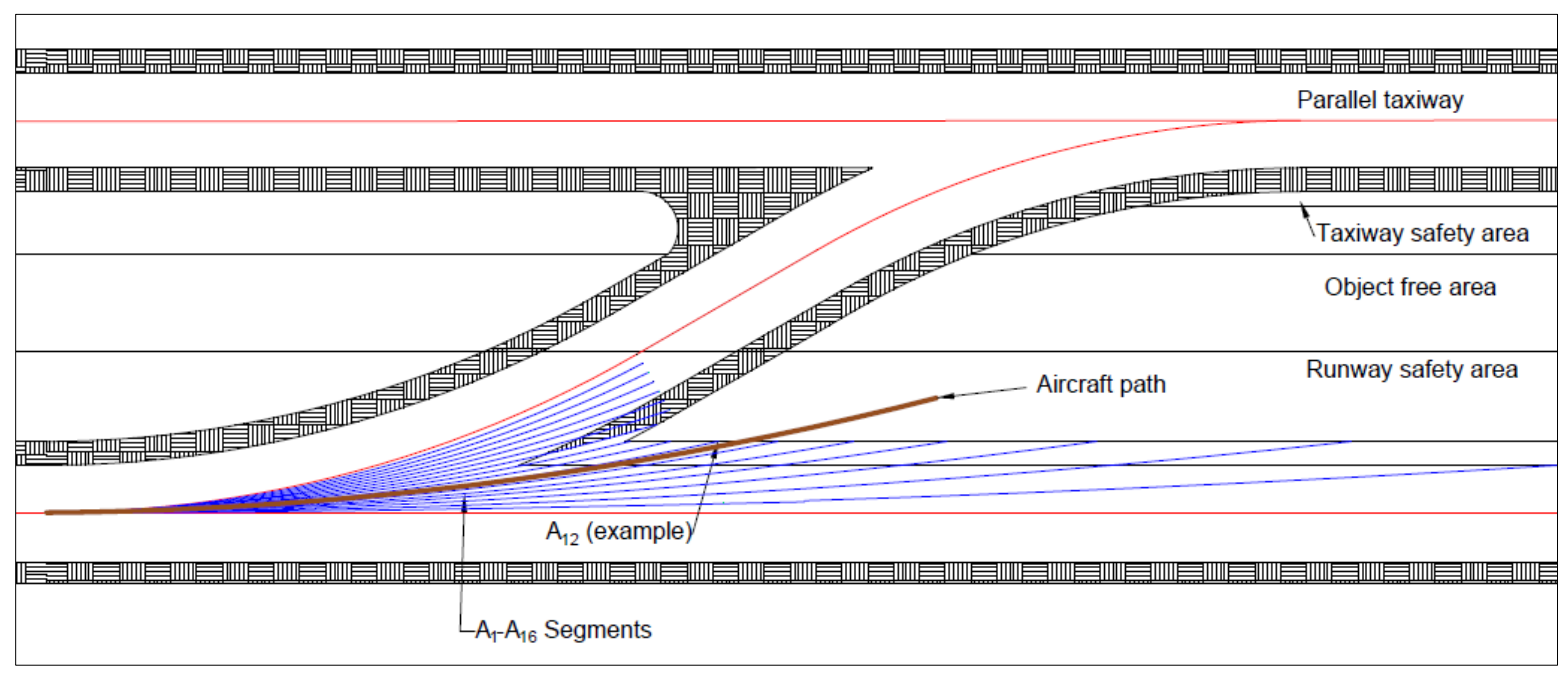

Figure 4. Curvilinear segments.

Table 3. Travel distance at each segment.

\begin{tabular}{cc}
\hline Radius of Curvature $\mathbf{R j}(\mathbf{m})$ & $\begin{array}{c}\text { Distance from the Point of Exit to the Point of } \\
\text { Veer-Off }(\boldsymbol{l})\end{array}$ \\
\hline $776-820$ & 295 \\
\hline $821-905$ & 287 \\
\hline $906-1007$ & 274 \\
\hline $1008-1133$ & 295 \\
\hline $1134-1292$ & 314 \\
\hline $1293-1496$ & 342 \\
\hline $1497-1769$ & 377 \\
\hline $1770-2151$ & 420 \\
\hline $2152-2726$ & 489 \\
\hline $2727-3684$ & 607 \\
\hline $3685-5594$ & 862 \\
\hline
\end{tabular}

Accordingly, the kinetic energy ratio is estimated and denoted as event severity (Equation (16)).

$$
D_{i}=\ddot{v}^{2} / v_{e x}^{2}
$$

Pilot skill, poor judgement, diverted attention, poor planning, unable to maintain speed, communication and coordination issues, experience and errors are some common human factors in line with the landing operations. Considering rapid exits related operations, pilot skill, poor judgment, poor planning of exits, unable to maintain speed, deceleration rates, and familiarity about the runway are key human factors. These factors may cause the exit speed to deviate from the recommended exit speed for a given exit. These factors are random, and their ultimate effect is on the exit speed. The random variations of these factors are covered as part of natural randomness by randomly varying the key parameters using the Monte Carlo simulation method. Thus, the randomness of the exit speed represents attached human factors in the event probability estimation. This is considered in the criticality factor estimation using the Monte Carlo simulation technique to obtain values for touchdown locations and touchdown speeds.

In the veer-off trajectory probability estimation, initial turn path selection depends on the exit speed. Pilot interventions may correct this turn path during the maneuver if it 
deviates from the taxiway centerline. As above-mentioned, considering random values for exit speeds, trajectory probability captures different human interventions. Other than that, this initial turn path radius is estimated as the maximum turn path radius to maintain the nose gear lateral stability. This over estimation is reasonable in terms of safety.

The use of random numbers for the operational variables is an indirect conjunction of human interventions into the methodology. As a sufficient number of accidents are not available for model calibration, this kind of approach has to proceed with a theoretical approach. Once an adequate amount of rapid exit-related incidents are recorded, the methodology can be fine-tuned by configuring the relevant human factors. Additionally, models can be improved by recalibrating against data obtained by flight simulators to account for variations in deceleration rates and application of braking with the intention of existing at varying locations.

\section{Analysis}

\subsection{Illustrative Example}

Table 4 shows the key parameters of an illustrative example developed to demonstrate the application of the proposed methodology, input parameters, and the outputs (for a given case) in each step. Aircraft (B747) touchdown speed, touchdown location, and exit location data were taken from an international airport in the US (Airport A) [33]. It is a hub airport having international flight operations. Weather conditions without any risk factors were considered.

Table 4. Aircraft veer-off probability calculation example.

\begin{tabular}{|c|c|}
\hline Aircraft Type & B747-400 \\
\hline Landing length required at distinct weather conditions for a given airport setting $\left(l_{0}\right)$ & $1986 \mathrm{~m}$ \\
\hline Recommended exit speed for the exit geometry $\left(v_{R}\right)$ & $27 \mathrm{~ms}^{-1}$ \\
\hline Touchdown speed (for the chosen operation) $(u)$ & $68.4 \mathrm{~ms}^{-1}$ \\
\hline Length required to reach to the recommended exit speed $\left(l_{R}\right)$ & $1676 \mathrm{~m}$ \\
\hline Exit location distance from threshold $\left(l_{a}\right)$ & $1650 \mathrm{~m}$ \\
\hline Modified criticality factor $\left(\mathrm{Cr}_{m}\right)$ & 0.00693 \\
\hline \multicolumn{2}{|l|}{ Using overrun risk model (Equation (2)), } \\
\hline Probability that the exit speed (Vex) exceeded the recommended exit speed at the exit location, (Event probability) - $P_{i}$ & $3.68 \times 10^{-5}$ \\
\hline \multicolumn{2}{|l|}{ Veer-off trajectory probability $\left(S_{i}\right)$ estimation } \\
\hline \multicolumn{2}{|l|}{ By Monte Carlo simulation } \\
\hline Touchdown location (using actual data or Monte Carlo simulation) & Estimate \\
\hline Deceleration in the landing roll (using actual data or Monte Carlo simulation) & Estimate \\
\hline $\begin{array}{l}\text { Aircraft exit speeds are estimated (Considering the above two simulated values and Equation (12), this is an } \\
\text { estimated value) }\end{array}$ & $40.6 \mathrm{~ms}^{-1}$ \\
\hline Side friction coefficient (Equation (11)) & 0.19 \\
\hline $\begin{array}{c}\text { Aircraft demand turning radius } R_{D} \text { estimate (Considering the above simulated values and Equation (10), this is an } \\
\text { estimated value) }\end{array}$ & $938 \mathrm{~m}$ \\
\hline \multicolumn{2}{|c|}{$\begin{array}{l}\text { Using Monte Carlo simulation for random variables for the touchdown location and deceleration, there may be distinct exit speeds and } \\
\text { consequent demand radiuses. For location probability estimation, random values are estimated for the exit speed. These distinct exit } \\
\text { speeds cause the aircraft to travel different turn path radiuses. These demand turning radiuses against the maximum allowable radius } \\
\text { (775 m) are identified and the respective percentage ratio is used as the location probability. }\end{array}$} \\
\hline Potential veer-offs are identified when $\mathrm{R}_{\mathrm{D}}>775 \mathrm{~m}, S_{i}$ (Depends on the simulated values and calculations) & 0.18 \\
\hline \multicolumn{2}{|l|}{ Severity estimation $\left(X_{i}\right)$} \\
\hline Deceleration during the turning maneuver (Depends in the simulated values) & $0.5 \mathrm{~ms}^{-2}$ \\
\hline Travel distance in the turning maneuver belonging to the (907-1006) $\mathrm{m}$ segment & $274 \mathrm{~m}$ \\
\hline Aircraft veer-off speed $\ddot{\mathrm{v}}($ Equation (15)) & $36.2 \mathrm{~ms}^{-1}$ \\
\hline Estimate severity $\left(\ddot{\mathrm{V}}^{2} / v_{e x}^{2}\right)$ in Equation $(16), X_{i}$ & 0.79 \\
\hline Aircraft veer-off risk with regard to major consequences $\left(P_{i} \times S_{i} \times X_{i}\right)$ & $4.16 \times 10^{-7}$ \\
\hline
\end{tabular}




\subsection{Results}

The implementation of this methodology for runway rapid exits at an airport (Airport A) is shown below. Accordingly, Table 5 shows the relevant runway length, exit locations (from the threshold), airport ambient temperature, and elevations. The veer-off risk estimated under these circumstances at three exits at the same touchdown speed is shown in Figure 5. The exit 1-8L, which is the closest exit to the runway threshold, is considered as the reference exit location. The estimated risks depict that closer exit locations have increased veer-off risk compared to the exit locations distant from the threshold.

Table 5. Runway data.

\begin{tabular}{cccc}
\hline Exit & $\begin{array}{c}\text { Exit 1-8L } \\
\text { (Reference) }\end{array}$ & Exit 2-8R & Exit 4-8R \\
\hline Runway length & $3202 \mathrm{~m}$ & $3202 \mathrm{~m}$ & $3202 \mathrm{~m}$ \\
\hline Exit location & $1450 \mathrm{~m}$ & $1650 \mathrm{~m}$ & $1950 \mathrm{~m}$ \\
\hline Elevation & $3 \mathrm{~m}$ & $3 \mathrm{~m}$ & $3 \mathrm{~m}$ \\
\hline Ambient temperature & $25-30{ }^{\circ} \mathrm{C}$ & $25-30{ }^{\circ} \mathrm{C}$ & $25-30^{\circ} \mathrm{C}$ \\
\hline
\end{tabular}

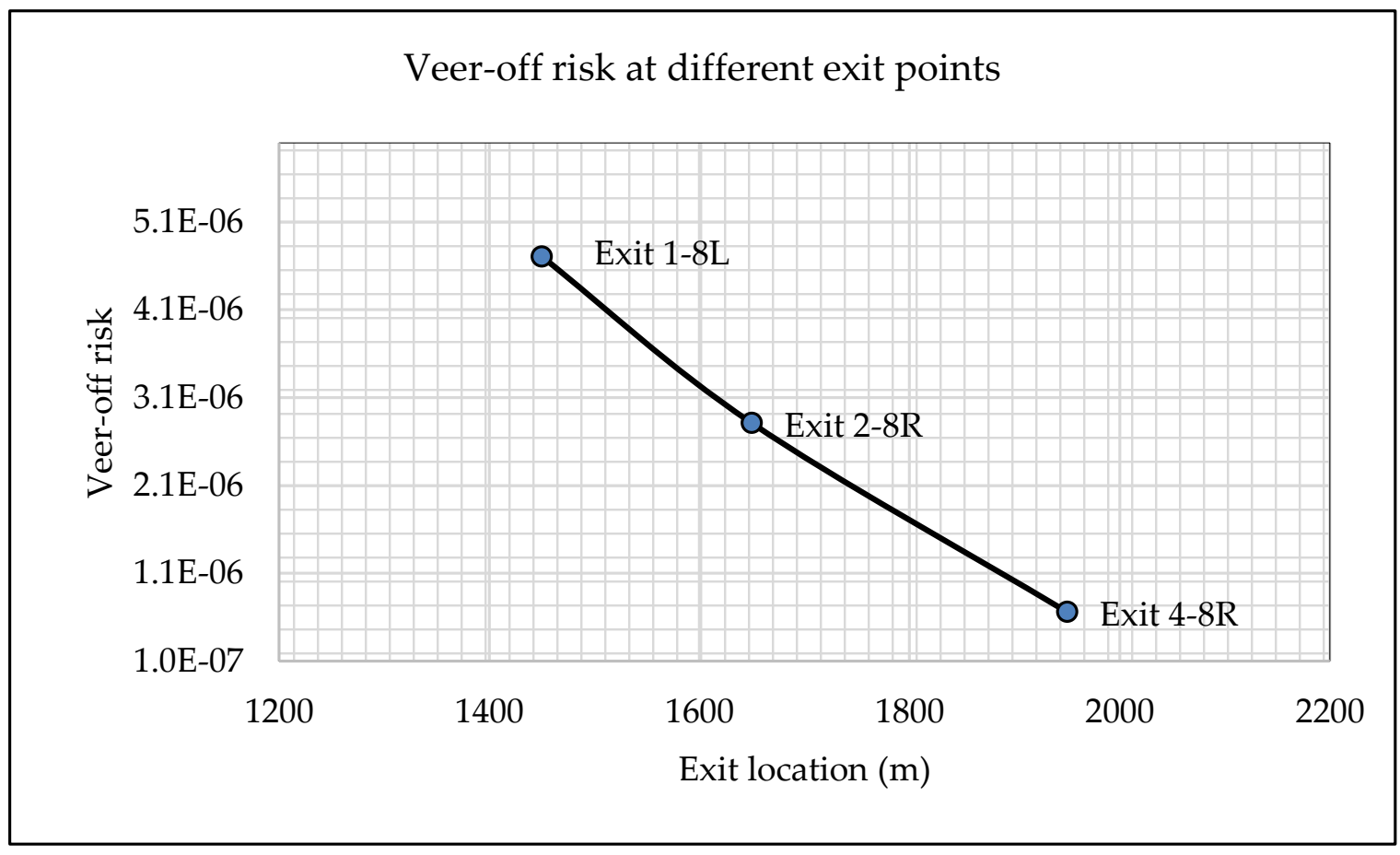

Figure 5. Veer-off risk vs. exit location.

Considering the veer-off risk at different exit locations, veer-off risk ( $y)$ could be identified as a function of the exit location $x$ (distance from the threshold to the point of exit). Thus, the following function (17) is developed subject to airport elevation and average ambient temperature readings. It shows that the veer-off risk decreases exponentially with the distance to the exit location.

$$
y=0.0017 e^{-0.004 x}
$$

where $y$ is the veer-off risk and $x$ is the distance to the exit location from the runway threshold.

The study estimated aircraft veer-off risk at the reference exit 1-8L at different tailwind conditions, as shown in Figure 6. In the event probability estimation (Equation (2)), the tailwind factor is split into three risk factors considering three distinct tailwind ranges 
such as less than 5 knots, between 5 and 12 knots, and above 12 knots. In each individual range, the corresponding effect is uniform. This is a direct effect, and it is not a linear effect. However, tailwind causes the required landing length to increase, and the effect of the tailwind on event probability again comes forward through the runway criticality factor. This is an indirect effect of tailwind. Thus, the combined effect is probably " $S$ " shaped and not linear. Increasing tailwinds increase the veer-off risk at rapid exits. Similar to exit locations, various weather conditions also affect the veer-off risk at rapid exit taxiways.

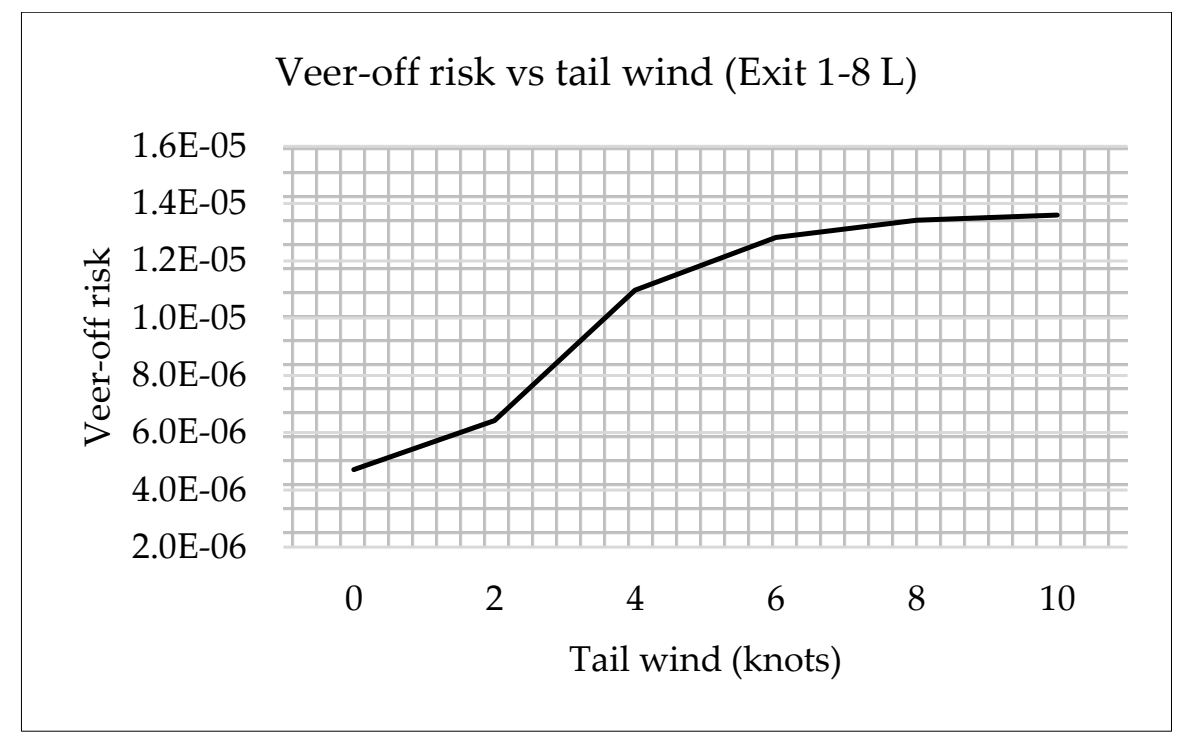

Figure 6. Veer-off risk vs. tail wind.

This paper analyzes the sensitivity of the exit location on aircraft veer-off risk. Using Equation (17), veer-off risk is estimated for exits located at regular intervals from the threshold. Estimated veer-off risks at various locations are compared with the risk of an exit that can be placed closest to the runway end. In this example, risk at various exit locations are compared with the veer-off risk of the exit placed $3000 \mathrm{~m}$ from the runway threshold. According to Figure 7, if an exit is placed $1000 \mathrm{~m}$ from the runway threshold, the corresponding veer-off risk rises by 58 times compared to an exit $2000 \mathrm{~m}$ from the threshold. Conversely, the veer-off risk decreases by 58 times when the exit at $2000 \mathrm{~m}$ is relocated at $3000 \mathrm{~m}$ distance. However, a longer rapid exit location may disrupt the intended purpose of such rapid exits. Therefore, the optimum exit location needs to be decided considering both the runway capacity and safety. Although the estimated values are valid only for the chosen runway condition, the methodology developed in this paper can be adapted to any airport to locate rapid exit taxiways.

Exit location is the key determinant on the runway occupancy time. Thus, exit location becomes the most important design parameters in rapid exit designs. As shown in Figure 7, when exits are closer to the threshold, it is observed that the corresponding veer-off risk increases. Consequently, an alternative approach could be practiced to minimize veer-off risk instead of increasing the distance to the point of exit. Wider taxiway widths and improved taxiway radii are such alternative approaches for risk minimization. The study estimated that a 30\% increase in exit radius reduces veer-off risk by $49 \%$ at the selected exit location. Similarly, widening the taxiway width by $30 \%$ reduces veer-off risk by $9 \%$ (Figure 8). 


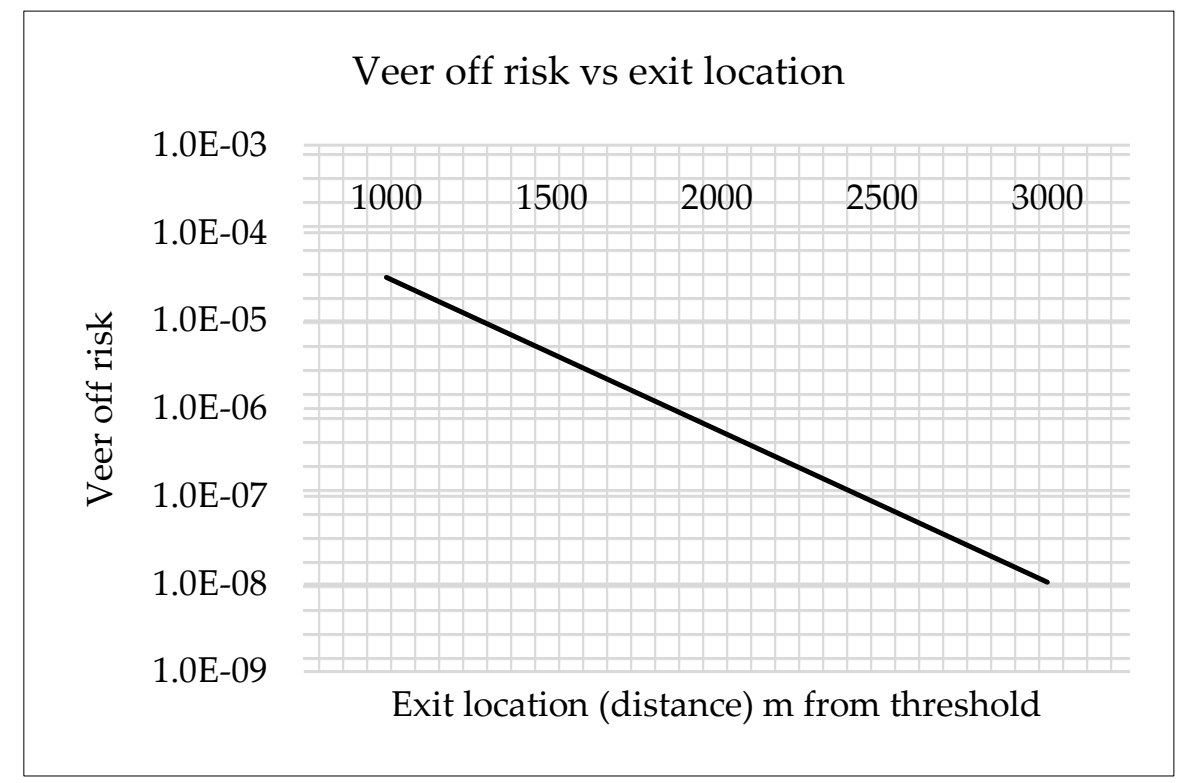

Figure 7. Exit location sensitivity.

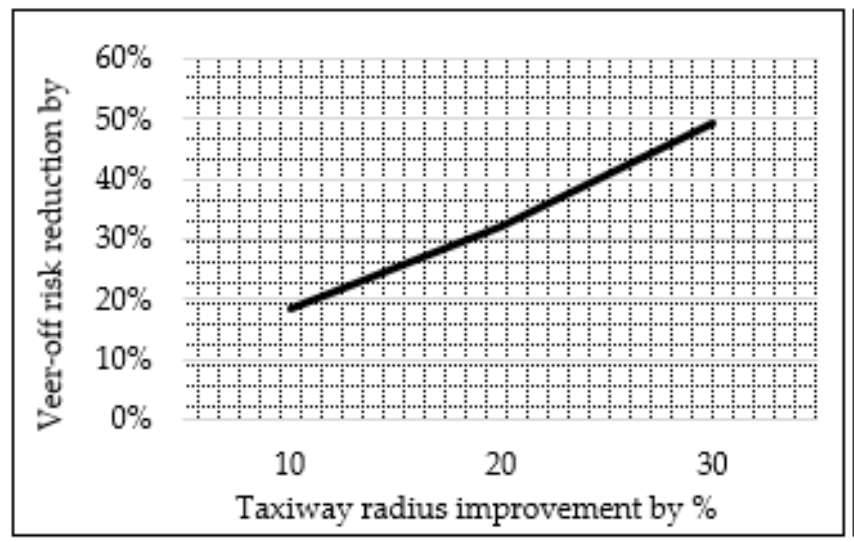

(a)

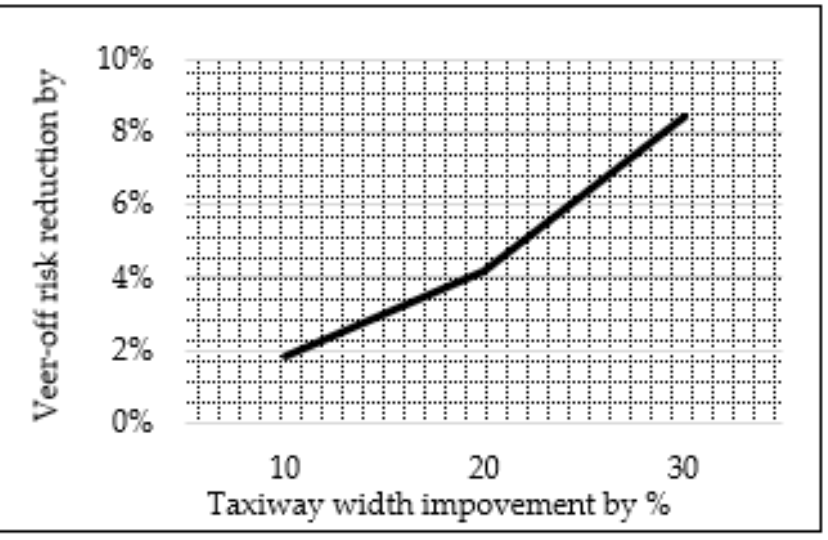

(b)

Figure 8. Veer-off risk reduction with design element improvements: (a) Percentage veer-off risk reduction with the percentage taxiway radius improvement; (b) Percentage veer-off risk reduction with the percentage taxiway width improvement.

To achieve the expected benefit of a runway rapid exit, pilots should accept and vacate through the planned exit. Thus, it is important to design safer and convenient rapid exits. In that sense, increasing veer-off risks due to advanced exit locations and various causal factors can be manipulated by the rapid exit design elements such as taxiway radii and width.

\section{Conclusions}

Runway operational capacity could be improved using rapid exit taxiways. Exit location and exit geometry are critical design parameters when the intended purpose of having a rapid exit is considered. The majority of the aircraft accidents at airports take place during the runway operations such as landings and take-offs. When the rapid exit taxiways are introduced for runways and aircraft landings frequently utilize rapid exits, aircraft accident rates at rapid exits may also increase significantly. Thus, estimating aircraft risk at rapid exit taxiways and consequent designs incorporating risk-based analysis for locating them are important preventive measures. 
Similar to frequent excursion event types during aircraft landings such as overruns and veer-offs, aircraft veer-off can take place during the high-speed turning maneuvers at rapid exits as well. Aircraft speed at the point of exit is the main operational factor that may lead an aircraft to travel in a different turn path radius with respect to the rapid exit taxiway centerline. Such a different turn path radius relates to the aircraft nose gear as a result of the lateral stability of the same gear caused by the lateral forces. The side friction coefficient and centripetal force are significant factors for these turning maneuvers. The analysis assumes that veer-off events at rapid exits are created by the occurrences at which aircraft exit speed exceeds the recommended exit speed. Thus, this paper assesses the probability that the aircraft speed exceeds the recommended exit speed, and it is considered as the event probability. A major constraint to developing an event probability model was the lack of normal operations and accident data. Thus, an existing overrun probability model is used to estimate the event probability that an exit speed exceeds the recommended speed. A major assumption made in the analysis is that factors affecting an aircraft to exceed the zero speed at the runway end has the same influence on the odds of the same aircraft to exceed the recommended exit speed at a given exit location. Accordingly, the overrun probability model is adapted here to estimate the event probability by modifying the runway criticality factor in the model. Aircraft deceleration during the landing roll is considered as a random number as it depends on the pilot's intention to take a particular exit. An alternative way of event probability estimation can be done using the Monte Carlo simulation technique, and it will be a part of the extension of this research in the future. Due to higher exiting speeds, the aircraft travel path may deviate from the taxiway centerline path. The aircraft curvilinear travel path beyond the maximum demand turning radius for a given aircraft type and exit geometry is taken into the veer-off trajectory probability estimation. Although pilot skills can correct such deviations, this is difficult to be assessed quantitatively and inserted into the analysis. For the purpose of the analysis, which is to compare the effects of runway characteristics on rapid exit risk, the human factor is ignored. Although it would cause for an over estimation, it is acceptable in terms of safety. In case of a veer-off, the respective kinetic energy ratio at the time of veer-off and at the turning maneuver starts is considered to assess the accident severity. The methodology notices runway, aircraft, and weather-related input data in the event probability estimation, and it is an advantage of this methodology.

According to the analysis, aircraft veer-off probabilities significantly drop when the distance increase from the threshold to the exit location. Furthermore, veer-off risk is high at lower side friction coefficients and aircraft are safe at all side friction coefficients of 0.4 or above. The analysis found that the aircraft speeds lower than the recommended exit speeds enable aircraft to follow the taxiway radius without any deviations. Additionally, weatherrelated factors such as tailwind, rain, wet runway conditions, etc. also increase veer-off risk at any given exit location due to the required landing length at such weather conditions.

According to the findings, exit locations advanced toward the landing threshold may compromise aircraft safety. Wider taxiways and a larger radius of curvatures aid to configure advance exit locations for higher exit speeds without compromising aircraft safety. Thus, this paper recommends exit taxiway design alternations such as wider taxiways and larger radius of curvatures to counteract against the increase in the risk of veer-off at HSE. The paper presents an approach to develop a quantitative risk analysis method for aircraft veer-off risk at different exit locations. It can be used to compare different design configurations and operational conditions. Accordingly, respective modifications for the design elements such as wider taxiways could also be quantitatively justified by this methodology. This is in line with the recommendations given in the draft FAA Advisory Circular on Airport Design, which recommends widening high-speed exit throats [9]. The problems arising with the methodology when it is adopted for other airports is the need for site-specific data. Site-specific weather data, aircraft touchdown speed, and location data need to be measured when different types of aircraft are operated. Considering fleet mix and the related approach category, touchdown locations and speeds can be approximately 
predicted. Furthermore, when different aircraft types are considered, the respective maximum allowable turning radiuses are also required to be geometrically derived. It depends on the aircraft landing gear configuration. Additionally, the scarcity of real operations data can be avoided by using methods such as flight simulators. Accordingly, pilots can simulate data when they are trying to exit at various exit locations and measure the relevant parameters. The study found that the increasing risk due to operational factors can also be compensated by the exit design elements. The proposed methodology can be easily extended to assess the specific issues once the necessary data are available at the airport.

Author Contributions: The authors confirm contributions to the paper as follows: Study Conceptualization, S.G. and H.R.P.; Formal analysis, S.G. and V.A.; Methodology, S.G. and V.A.; Resources, H.R.P.; Supervision, V.A. and H.R.P.; Writing—original draft, S.G.; Writing—review and editing, V.A. and H.R.P. All authors have read and agreed to the published version of the manuscript.

Funding: The authors wish to thank the University of Moratuwa, Senate Research Committee for providing support for research publication.

Institutional Review Board Statement: Not applicable.

Informed Consent Statement: Not applicable.

Data Availability Statement: Not applicable.

Acknowledgments: We are highly thankful to the academic staff of the department of Civil Engineering, University of Moratuwa, Sri Lanka who was greatly assisted during this research.

Conflicts of Interest: The authors declare no conflict of interest.

\section{References}

1. International Airport Review. Available online: https://www.internationalairportreview.com/article/101952/world-airporttraffic-report-preview-aciworld/ (accessed on 22 January 2021).

2. Hamzawi, S.G. Lack of airport capacity: Exploration of alternative solutions. Transp. Res. Part. A Policy Pract. 1992, 26, 47-58. Available online: https://www.sciencedirect.com/science/article/abs/pii/0965856492900448?via\%3Dihub (accessed on 14 February 2021). [CrossRef]

3. Dray, L. An empirical analysis of airport capacity expansion. J. Air Transp. Manag. 2020, 87. [CrossRef]

4. Horonjeff, R.; McKelvey, F.; Sproule, W.; Young, S. Planning and Design of Airports; Mc Graw Hill, Inc.: New York, NY, USA, 2010.

5. International Civil Aviation Organization. ICAO-Doc 9157-AN 901-Aerodrome Design Manual Part 2 Taxiways Aprons and Holding Bays. 2005. Available online: https://www.academia.edu/41316519/Doc_9157_Aerodome_design_manual_part_2 taxiway_up_date (accessed on 15 December 2020).

6. Clemmer, C.B. Determining the Location of Runway Exits Using Airport Surface Detection Equipment. Master's Thesis, EmbryRiddle Aeronautical University, Daytona Beach, FL, USA, 2018. Available online: https://commons.erau.edu/cgi/viewcontent. cgi? article $=1420 \&$ context $=$ edt (accessed on 15 January 2021).

7. Hall, J.; Ayres, M.; Shirazi, H.; Speir, R.; Carvalho, R.; David, R. Airport Cooperative Research Program Report 51: Risk Assessment Method to Support Modification of Airfield Separation Standards; Transportation Research Board: Washington, DC, USA, 2011; Available online: http://nap.edu/14501 (accessed on 28 December 2020).

8. Hall, J.; Ayres, M.; Wong, D.; Appleyard, A.; Eddowes, M.; Shirazi, H. Airport Cooperative Research Program Report 3: Analysis of Aircraft Overruns and Undershoots for Runway Safety Areas; Transportation Research Board: Washington, DC, USA, 2008; Available online: https:/ / www.icao.int/SAM/Documents/2011/AGAASEROSTUDIES/ACRP_rpt_003.pdf (accessed on 20 December 2020).

9. Federal Aviation Administration. Advisory Circular No: 150/5300-13B. 2020. Available online: https://www.faa.gov/ documentLibrary/media/Advisory_Circular/draft-150-5300-13B-industry.pdf (accessed on 15 October 2020).

10. Boeing Commercial Airplanes. Aviation Safety, Boeing Commercial Airplanes: Statistical Summary of Commercial Jet Airplane Accidents 1959-2016; Boeing Airplane: Chicago, IL, USA, 2018; Available online: https://www.skybrary.aero/bookshelf/books/4239.pdf (accessed on 24 December 2020).

11. Skybrary. Accidents and Incidents. 2020. Available online: https://www.skybrary.aero/index.php/Accident_and_Serious_ Incident_Reports_RE (accessed on 3 October 2020).

12. Kirkland, I.D. The Risk Assessment of Aircraft Runway Overrun Accidents and Incidents. PhD Thesis, Loughborough University, Loughborough, UK, 2001. Available online: https://repository.lboro.ac.uk/articles/The_risk_assessment_of_aircraft_runway_ overrun_accidents_and_incidents/9456605 (accessed on 17 November 2020). 
13. Wong, K.Y. The Modelling of Accident Frequency Using Risk Exposure Data for the Assessment of Airport Safety Areas; Loughborough University: Loughborough, UK, 2007; Available online: https://core.ac.uk/download/pdf/288389973.pdf (accessed on 12 November 2020).

14. Van Es, G.W.H.; Tritscheler, K.; Tauss, M. NLR Report-TP-2009-280: Development of a landing Overrun Risk Index; Air Transport Safety Institute: Amsterdam, The Netherlands, 2009; Available online: https://reports.nlr.nl/xmlui/bitstream/handle/10921/23 5/TP-2009-280.pdf (accessed on 2 January 2021).

15. Guerra, L.; Murino, T.; Romano, E. Airport system analysis: A probabilistic risk assessment model. Int. J. Syst. Appl. Eng. Dev. 2008, 2, 52-65.

16. Ayres, M.; Carvalho, R.; Shirazi, H.; David, R. Airport Cooperative Research Program Report 107: Development of a Runway Veer-Off Location Distribution Risk Assessment and Reporting Template; Transportation Research Board: Washington, DC, USA, 2014; Available online: https: / / www.nap.edu/download/22411 (accessed on 24 December 2020).

17. Jeon, J.; Song, J.; Kim, H.; Song, B. Research on the Advanced Risk Assessment of Runway Safety Areas with Enhanced Algorithm. Int. J. Eng. Sci. Technol. 2016, 5, 67-70. [CrossRef]

18. Shirazi, H.; Hall, J.; Williams, B.; Moser, S.; Boswel, D.; Hardy, M. Airport Cooperative Research Program Report 168: Runway Protection Zones (RPZ) Risk Assessment Tool Users' Guide; Transportation Research Board: Washington DC, USA, 2016; Available online: https: / / www.nap.edu/download/24662 (accessed on 4 January 2021).

19. Moretti, L.; Cantisani, G.; Caro, S. Airport Veer-off Risk Assessment: An Italian Case Study. J. Eng. Appl. 2017, 12, 900-912.

20. Trucco, P.; De Ambroggi, M.; Leva, M.C. Topological risk mapping of runway overruns: A probabilistic approach. Reliab. Eng. Syst. Saf. 2015, 142, 433-443. [CrossRef]

21. Schoen, M.L.; Preston, O.W.; Summers, L.G.; Nelson, B.A.; VanderLinden, L.; Reynolds, M.C. NASA Contractor Report: 172549: Probabilistic Computer Model of Optimal Runway Turnoffs; Langley Research Center: Hampton, VA, USA, 1985.

22. Trani, A.A.; Hobeika, A.G.; Sherali, H.D.; Kim, B.J.; Sadam, C.K. Report DOT/FAA/RD-90/32,I: Runway Exit Designs for Capacity Improvement Demonstrations Phase I Algorithm Development; Center for Transportation Research, Virginia Polytechnic Institute and State University: Blacksburg, VA, USA, 1990. Available online: https://ntrs.nasa.gov/archive/nasa/casi.ntrs.nasa.gov/19910007 752.pdf (accessed on 17 October 2020).

23. Trani, A.A.; Hobeika, A.G.; Kim, B.J.; Nunna, V.; Zhong, C. Report DOT/FAA/RD-920/16,II: Runway Exit Designs for Capacity Improvement Demonstrations Phase II Computer Model Development; Center for Transportation Research, Virginia Polytechnic Institute and State University: Blacksburg, VA, USA, 1992. Available online: https://ntrs.nasa.gov/api/citations/19920011919/ downloads /19920011919.pdf (accessed on 21 April 2021).

24. Rammohan, K.S.; Mahesh, K.M. Determining the Location of Rapid Exit Taxiways Using Three Segment Method. Int. J. Innov. Res. Sci. Eng. Technol. 2017, 6, 1715-1718. [CrossRef]

25. Rahim, J. An Analysis of Runway Capacity at International Airport Sultan Aji Sulaiman Balikpapan in East Kalimantan-Indonesia. Int. J. Eng. Sci. 2015, 4, 5-11. Available online: http://www.irjes.com/Papers/vol4-issue5/B450511.pdf (accessed on 25 February 2021).

26. Meijers, N.P.; Hansman, R.J. Report No. ICAT-2019-14: Data-Driven Predictive Analytics of Runway Occupancy Time for Improved Capacity at Airports; MIT International Center for Air Transportation, Massachusetts Institute of Technology: Cambridge, MA, USA, 2019.

27. Zhou, H.; Jiang, X. Research on Taxiway Path Optimization Based on Conflict Detection. PLoS ONE 2015, 10, e0134522. [CrossRef] [PubMed]

28. Scholz, F. Statistical Extreme Value Analysis of ANC Taxiway Centerline Deviations for 747 Aircraft; The Boeing Company: Chicago, IL, USA, 2003. Available online: https://www.faa.gov/airports/resources/publications/reports/media/JFK_101703.pdf (accessed on 17 July 2020).

29. Young, S. Centerline Deviations; Center for Aviation Studies, The OHIO State University: Columbus, OH, USA, 2015; Available online: https:/ / aviation.osu.edu/research/centerline-deviation (accessed on 11 November 2020).

30. Federal Aviation Administration. Airport Design Advisory Circular; FAA AC 150/5300-13A; U.S. Department of Transportation, Federal Aviation Administration: Washington, DC, USA, 2014. Available online: https://www.faa.gov/documentLibrary/ media / Advisory_Circular/150-5300-13A-chg1-interactive-201612.pdf (accessed on 25 January 2021).

31. Galagedera, S.D.B.; Pasindu, H.R.; Adikariwattage, V.V. Analysis of Aircraft Veer-off Probability at High Speed Exits. In Proceedings of the 2019 Moratuwa Engineering Research Conference (MERCon), Moratuwa, Sri Lanka, 3-5 July 2019. [CrossRef]

32. Air Services. Available online: www.airservicesaustralia.com/wp-content/uploads/Melbourne-Runway-Occupancy-Time.pdf (accessed on 21 December 2020).

33. Trani, A.A.; Hinze, N.; Mirmohammadsadeghi, N.; Duffy, K.; Vitagliano, L. Runway Exit Design Interactive Model; Air Transportation Systems Laboratory, Virginia Tech: Blacksburg, VA, USA, 2020. 